Portland State University

PDXScholar

\title{
A Cultural, Linguistic, and Ecological Framework for Response to Intervention With English Language Learners
}

Julie Esparza Brown

Portland State University, jebrown@pdx.edu

Jennifer Doolittle

Office of Special Education Programs, US Department of Education

Follow this and additional works at: https://pdxscholar.library.pdx.edu/edu_fac

Part of the Educational Methods Commons, and the Special Education and Teaching Commons Let us know how access to this document benefits you.

Citation Details

Brown, J., \& Doolittle, J. (2008). A Cultural, Linguistic, and Ecological Framework for Response to Intervention With English Language Learners. Teaching Exceptional Children, 40(5), 66-72.

This Article is brought to you for free and open access. It has been accepted for inclusion in Education Faculty Publications and Presentations by an authorized administrator of PDXScholar. Please contact us if we can make this document more accessible: pdxscholar@pdx.edu. 


\title{
A Cultural, Linguistic, and Ecological Framework for Response to Intervention With English Language Learners
}

\author{
Julie Esparza Brown \\ Portland State University \\ Jennifer Doolittle \\ Office of Special Education Programs, U.S. Department of Education
}

The Council for Exceptional Children is pleased to partner with the National Center for Culturally Responsive Educational Systems (NCCREST) to periodically include in TEACHING Exceptional Children topical briefs to support your efforts in addressing the learning needs of exceptional students from culturally and linguistically diverse backgrounds.

Response to Intervention (RTI) has been heralded by many as the long-awaited alternative to using a discrepancy formula for special education eligibility decisions. Use of the discrepancy formula for eligibility decisions has commonly been called a "wait to fail model" (Donovan \& Cross, 2002; Fuchs, Mock, Morgan \& Young, 2003; Mellard, 2004) because in this paradigm, students proceeded through long pre-referral, formal referral, and assessment processes prior to getting help in special education programs. By the time students received assistance, they were often too far behind to ever catch up, even with individualized support.

RTI instead focuses on intervening early through a multi-tiered approach where each tier provides interventions of increasing intensity. It includes the practice of screening all children early in their education to identify those who are not responding to classroom instruction and providing support through the use of research-based interventions at each tier while monitoring progress frequently (Batsche, Elliott, Graden, Grimes, Kovaleski, Prasse, et. al., 2005). RTI has the potential to affect change for English language learners (ELLs) by requiring the use of research-based practices based on individual children's specific needs. All ELLs, however, need culturally and linguistically appropriate instruction no matter the educational setting. In other words, instruction and interventions must consider a student's cultural background and experiences as well as their linguistic proficiency (in both English and the native language) in order for instruction to be appropriate. The focus of this brief is to provide an initial framework in the use of RTI that considers students' life experiences, including their language proficiencies in their first and second language, as well as the contexts in which they are taught.

\section{Opportunity to Learn}

As conceptualized, RTI is predicated upon effective, research-based and appropriate instruction in the general education classroom or Tier 1 . That is, it is assumed that all students are provided with scientifically validated instruction delivered with a high degree of fidelity to the curriculum, and thus all children are provided with an equal opportunity to learn. This, however, is problematic for ELLs in several ways. First, since RTI currently focuses on literacy, it is important to examine the existing reading research for ELLs. Although there is a growing body of research on effective reading instruction for ELLs with and without disabilities (Artiles \& Klingner, 2006; Linan-Thompson, Bryant, Dickson, \& Kouzekanani, 2005), it appears that not all ELLs are receiving appropriate literacy instruction (D’Angiulli, Siegel, \& Maggi, 2004; Saenz, Fuchs, \& Fuchs, 2005). Less than
$20 \%$ of the $56 \%$ of public school teachers in the U.S. who have at least one ELL in their class are certified to teach ELLs (Waxman, Tellez \& Walberg, 2004). Thus, most teachers lack the training, expertise, and experience in teaching reading and other subjects to ELLs. The second issue is that most multidisciplinary school teams charged with making special education eligibility decisions for ELLs also lack the training and experience in differentiating language difference from a learning disability (Collier, 2001; Flanagan \& Ortiz, 2001; Klingner, Artiles, \& Barletta, 2006; Ortiz, 1997). Consequently, the use of RTI without a foundation in culturally and linguistically appropriate instruction may lead to greater disproportionality (both under and over representation) of ELLs in special education.

To summarize, an appropriate foundation for RTI must include knowledge of each child's particular set of life experiences, and how these experiences may facilitate learning in an American school system. It is essential to address teacher-related and school-related issues as well as child traits. Further, all educators must be knowledgeable in first and second language acquisition principles and culturally responsive pedagogy, as well as have access to specialists who are well-trained in differentiating cultural and linguistic differences from disabilities. We provide an 
initial framework for understanding children's backgrounds below.

\section{The Framework}

Personalized instruction lies at the very heart of RTI in that each child's unique needs are evaluated and appropriate instruction provided so that all children have opportunities to succeed in our schools. As evidenced by the current achievement gap as well as the disproportionate representation of culturally and linguistically diverse children in special education programs, many of these students are underachieving. To ensure that RTI does not become one more discriminatory system, a framework for RTI addressing the needs of ELLs is required. This includes: (a) a systematic process for examining the specific background variables or ecologies of ELLs (i.e., first and second language proficiency, educational history including bilingual models, immigration pattern, socioeconomic status, and culture) that impact academic achievement in a U.S. classroom; (b) examination of the appropriateness of classroom instruction and the classroom context based on knowledge of individual student factors; (c) information gathered through informal and formal assessments; and (d) nondiscriminatory interpretation of all assessment data.

\section{RTI: A Tiered Intervention Approcich}

Experts promote two distinct RTI models (Bradley, Danielson, \& Hallahan, 2002; Fuchs, Mock, Morgan \& Young, 2003): a standard treatment protocol model and a problem-solving model, though in reality most school districts use a combination of the two (National Association of State Directors of Special Education [NASDE], 2006). According to NASDE, both models outline tiers or stages of interventions (Figure 1). In the standard treatment protocol model, the same empirically validated treatment is used for all children with similar problems, and achievement is measured against specified benchmarks. The problem-solving model is more flexible, as explained by NASDE as well: problems are defined behaviorally, interven- tions are planned specifically for the targeted student and provided over a reasonable period of time, performance is measured in the natural setting, and students' progress is compared to that of peers.

Beyond the approach to intervention planning, another difference in the various RTI models is the number of tiers. Generally, models include three or four tiers. In this brief, a three-tiered framework is outlined, which (in this case "that" is the defining pronoun, so should be used instead of "which") considers students' ecologies, cultural and linguistic needs, and the skills that members of an educational team must possess when an ELL student becomes a focus of concern.

\section{Tier 1 : Universal Screening and Research-Based Instruction}

At Tier 1, baseline data through universal screening are gathered for all students and achievement is monitored regularly. An RTI system relies on the use of evidence-based curricula that is taught in a manner consistent with its authors' intent (treatment integrity). It is assumed that effective and researchbased instruction already occurs in the general education classroom for all students. For ELLs, as discussed earlier, for instruction to be "effective and appropriate," assessment as well as instruction must be both linguistically and culturally congruent. That is, the teacher who wants to teach ELLs appropriately and effectively must know their levels of language proficiency in their first language (L1) and second language (L2) when planning assessment and instruction, and provide culturally relevant curricula that reflect the background and experiences of the students (Delpit, 1995; Gay, 1989; Macedo \& Bartolome, 1999). Appropriate instruction for ELLs requires that teachers embrace a pedagogy that is "rooted in the cultural capital of [their students] and have as its point of departure the native language and culture" (Freire \& Macedo, 1987, p. 151). In other words, a child's language and culture are never viewed as liabilities but rather as strengths upon which to build an education. When an ELL student becomes a focus of concern, the

\section{Figure 1. Response to Intervention: Three-Tier Model for ELLs}

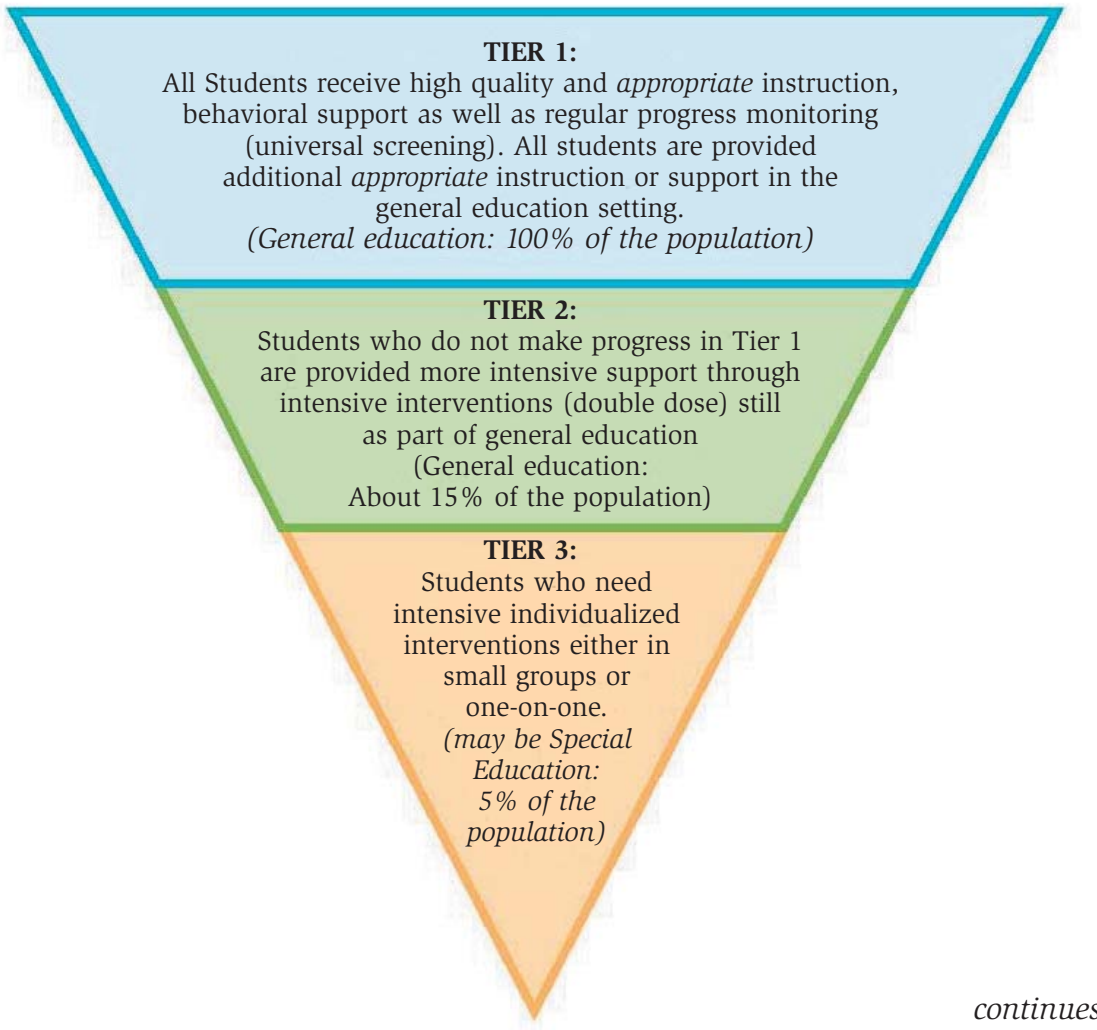


Figure 1 - Continued

\section{RTI for ELLs Flowchart}

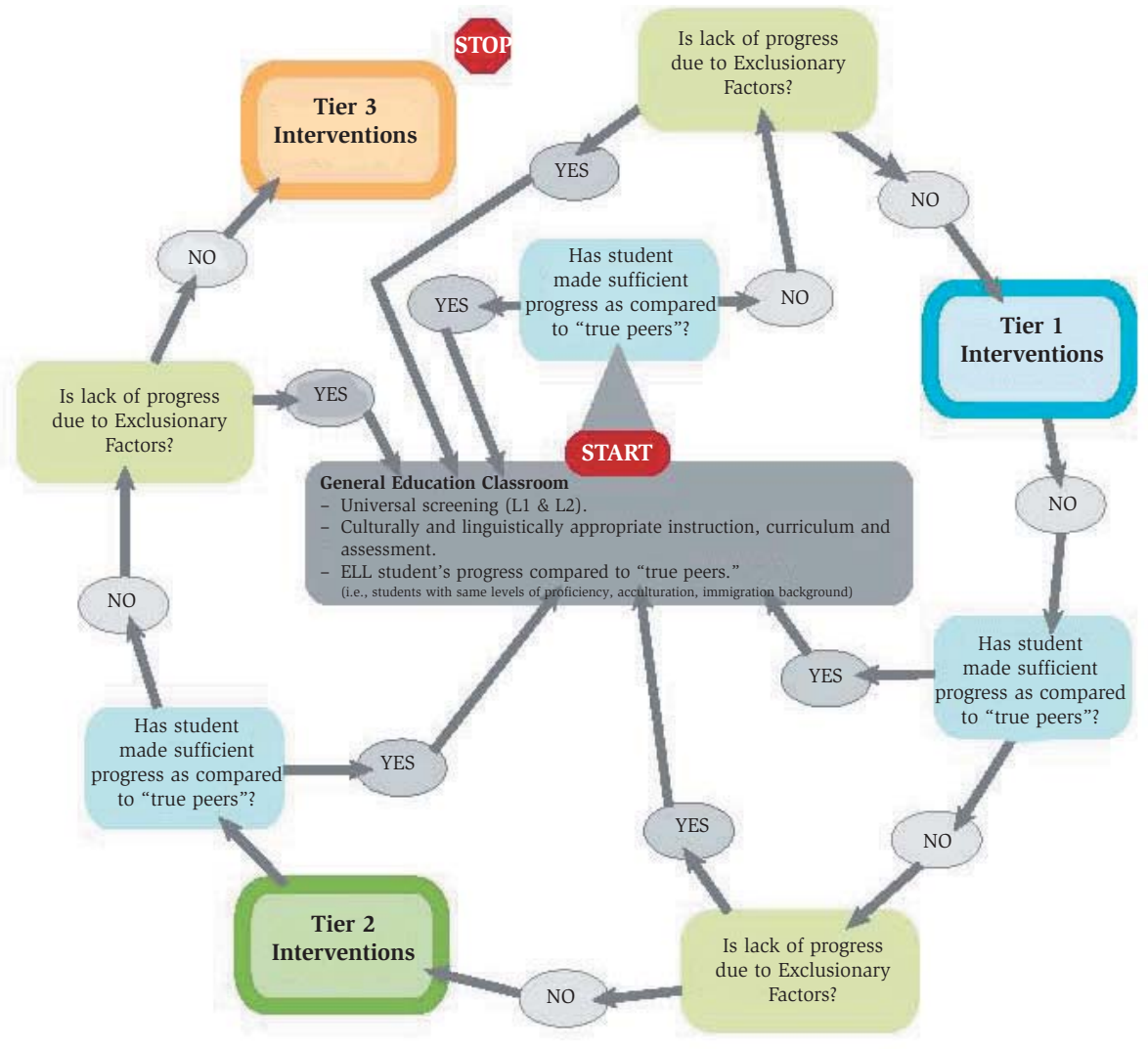

Tier 1 Interventions

Review of student's ecology (i.e.,

educational history, language profi-

ciency in L1 and L2, family education

and literacy, acculturation level, SES,

etc.

Interventions are developmentally,

culturally, linguistically and

experientially appropriate for targeted

students and may be the classroom

curriculum but a "double dose" or

extension of classroom curriculum

Interventions provide by classroom

teacher, instructional assistant or other

specialist within the general education

classroom in a small group

\section{Tier 2 Interventions}

Small group in or outside of general

education classroom

Interventions are linguistically,

culturally and experientially

appropriate

- Interventions counter to address

specific problem areas and progress

is closely monitored

Tier 3 Interventions

Small Group or 1:1 instruction with alternative curriculum in alternative setting

Curriculum and instruction addresses the specific deficit(s)

Interventions must continue to be

culturally, linguistically and

experientially appropriate

experientially appropriate

and L2 could be considered at this

tier to identify learning profiles

DECISION-MAKING POINT

FOR SPECIAL EDUCATION

CONSIDERATION

- If the student has not made sufficient progress, a psychoeducational evaluations may be considered that links to interventions.

Parent rights and consent are required

for standardized assessments.

All information must be provided to

parents in their native language,

including parent rights.

Using a discrepancy formula approach

for learning disability is appropriate

for ELL students.

Interpretation of standardized test dat

must be done within the context of

the student's language proficiency in

L1 and L2 acculturation level.

IEP goals must consider the student's

developmental, cognitive, cultural,

and linguistic abilities. instructional program itself must be examined to determine the match between the demands of the curriculum and the child's current level of proficiency in the language of instruction. It is important to examine the achievement of the student's "true peers" (similar language proficiencies, culture and experiential background) to see if they are excelling or not. If several "true peers" are struggling, this is an indication that the instruction is less than optimal for that group of students.

At Tier 1, once instruction is adjusted to meet each student's individual or personalized needs, progress is closely monitored and decisions are made as to whether students are meeting predetermined targets or benchmarks. If, after providing instructional modifications that could include re-teaching, smaller groupings in the general education classroom, or perhaps some instruction in a child's L1, the student does not make the targeted gains, it may be recommended that the student receive Tier 2 support. A table is provided below to help delineate factors that must be examined for ELLs at Tier 1, as well as the kinds of instructional support and personnel who can provide the needed instruction.

\section{Tier 2: More Intensive Support}

In Tier 2, interventions, rather than just instructional adjustments to the general curriculum, are provided to the student. Tier 2 interventions are often delivered in a small group setting and may be provided by a specialist (i.e., Title I teacher, reading specialist, special education teacher, speech and language specialist), or by the classroom teacher. Tier 2 interventions are supplemental to the general education curriculum. In other words, students should receive a "double dose" of instruction targeted at specific goals based on students' needs identified by Tier 1 screening. As stated 
Tier 1:

\section{POPULATION: ALL STUDENTS SETTING: GENERAL EDUCATION}

\begin{tabular}{|c|c|}
\hline $\begin{array}{l}\text { STUDENT } \\
\text { CHARACTERISTICS }\end{array}$ & $\begin{array}{l}\text { Achievement is both at a lower level when compared to "true-peers" (same levels of language } \\
\text { proficiency, acculturation, and educational background) and occurs at a substantially slower rate }\end{array}$ \\
\hline $\begin{array}{l}\text { GUIDING } \\
\text { QUESTIONS }\end{array}$ & $\begin{array}{l}\text { - Is scientifically-based instruction in place for the target student and consideration given to his/her } \\
\text { cultural, linguistic, socioeconomic and experiential background? } \\
\text { - Is instruction targeted to the student's level of English proficiency? } \\
\text { - Is the concern examined within the context (i.e., language of instruction, acculturation)? } \\
\text { - Have the parents been contacted and their input documented? } \\
\text { - Has accurate baseline data been collected on what the student can do as well as what he/she } \\
\text { must still learn? } \\
\text { - Are L1 and L2 language proficiency monitored regularly? } \\
\text { - Have the ecology of the classroom and school been assessed? } \\
\text { - What were the child's pre-school literacy experiences, if any? } \\
\text { - Have hearing and vision been screened? } \\
\text { - What tasks can the student perform and in what settings? } \\
\text { - Have specific Tier } 1 \text { RTI interventions that are culturally, linguistically and experientially } \\
\text { appropriate been developed? }\end{array}$ \\
\hline $\begin{array}{l}\text { INSTRUCTION/ } \\
\text { INTERVENTION }\end{array}$ & $\begin{array}{l}\text { - All students receive high-quality, research-based instruction by qualified staff } \\
\text { - Universal screening of academics and behavior of all students to identify those who need close } \\
\text { monitoring or intervention } \\
\text { - Progress monitoring compares ELL student to other true-peer ELLs since their rate of progress } \\
\text { cannot be compared to that of the English-only group } \\
\text { - Appropriate instructional interventions are developed such as individually designed instructional } \\
\text { units, or different instruction using the general education curriculum } \\
\text { - Background knowledge is built } \\
\text { - Research-based interventions are implemented for at least } 8-12 \text { weeks and progress is monitored } \\
\text { - Culturally responsive instruction is fundamental at this tier and not an add-on } \\
\text { - Explicit and linguistically appropriate instruction is also fundamental (attention given to language } \\
\text { forms and functions) } \\
\text { - Strategies appropriate for instructing ELLs such as Total Physical Response, visuals, real objects, } \\
\text { modeling, repetitive language and gestures must be used } \\
\text { - Instruction includes language activities and explicit instruction in phonological awareness, the } \\
\text { alphabetic code, vocabulary development and comprehension strategies } \\
\text { - Instruction in the native language is provided }\end{array}$ \\
\hline $\begin{array}{l}\text { SERVICE } \\
\text { PROVIDER }\end{array}$ & $\begin{array}{l}\text { - If the course topics remain the same, what new research, examples, and writings can illustrate } \\
\text { these topics? } \\
\text { - Is there a new thematic approach to this material that will help to put cultural diversity in the } \\
\text { foreground? } \\
\text { - How do I integrate new material so that it is not simply an "add-on"? } \\
\text { - What teaching strategies will facilitate student learning of this new material? }\end{array}$ \\
\hline $\begin{array}{c}\text { NECESSARY } \\
\text { SERVICE PROVIDER } \\
\text { SKILLS }\end{array}$ & $\begin{array}{l}\text { Able to: } \\
\text { - provide developmentally, culturally, linguistically and experientially appropriate instruction and } \\
\text { assessment to all students } \\
\text { - deliver culturally responsive instruction } \\
\text { - describe behaviors/areas in observable terms and establish baselines } \\
\text { - identify the elements that will lead to success in the identified problem area } \\
\text { - identify instructional and student variables that may contribute to a solution } \\
\text { - understand that no student characteristic (e.g., disability label, race, SES, cultural group) } \\
\text { dictates a priori what intervention will work } \\
\text { - collaborate with other service providers and parents } \\
\text { - use tools that assess L1 and L2 skills }\end{array}$ \\
\hline
\end{tabular}


Tier 2:

POPULATION: STUDENTS WHO NEED DIFFERENT AND MORE INTENSIVE INSTRUCTION THAN PROVIDED IN TIER 1 SETTING: SMALL GROUP SETTING

\begin{tabular}{|c|c|}
\hline $\begin{array}{l}\text { STUDENT } \\
\text { CHARACTERISTICS }\end{array}$ & $\begin{array}{l}\text { Achievement continues both at a lower level as compared to "true-peers" and occurs at a } \\
\text { substantially slower rate }\end{array}$ \\
\hline $\begin{array}{l}\text { GUIDING } \\
\text { QUESTIONS }\end{array}$ & $\begin{array}{l}\text { - Will instruction in a small group setting lead to success? } \\
\text { - Has the student's progress been compared to him or herself using data collected over time and } \\
\text { across settings? } \\
\text { - Does the child's learning rate appear to be lower than that of an average learning "true peer"? } \\
\text { - Is the child responding to interventions? } \\
\text { - Will an alternate curriculum help the student succeed? } \\
\text { - Is scientifically-based instruction in place for the target student and consideration given to his/her } \\
\text { cultural, linguistic, socioeconomic and experiential background? }\end{array}$ \\
\hline $\begin{array}{l}\text { INSTRUCTION/ } \\
\text { INTERVENTION }\end{array}$ & $\begin{array}{l}\text { - Option of receiving different curriculum from Tier } 1 \text { (time and intensity) which would be } \\
\text { systematic and explicit instruction with modeling, multiple examples, and feedback } \\
\text { - This supplementaL instruction is in addition to the time allowed for core reading instruction in } \\
\text { general education } \\
\text { - The curriculum addresses the student's specific learning needs and progress is carefully monitored } \\
\text { and reported } \\
\text { - Observations should occur across settings and be of various activities/tasks } \\
\text { - If the student does not respond to Tier } 2 \text { interventions, consider referring to Tier } 3\end{array}$ \\
\hline $\begin{array}{l}\text { SERVICE } \\
\text { PROVIDER }\end{array}$ & $\begin{array}{l}\text { - Specialist (Title I Teacher, Reading Teacher, Special Education Teacher, Related Service Provider) } \\
\text { or General Education Teacher } \\
\text { - General education teacher responsible for integrating all tiers of instruction into the classroom } \\
\text { and monitoring instruction }\end{array}$ \\
\hline $\begin{array}{c}\text { NECESSARY } \\
\text { SERVICE PROVIDER } \\
\text { SKILLS }\end{array}$ & $\begin{array}{l}\text { Able to: } \\
\text { - ensure that culturally and linguistically appropriate classroom instruction was provided in Tier } 1 \\
\text { and continues in Tier } 2 \\
\text { - accurately monitor and report student's progress and adjust instruction accordingly }\end{array}$ \\
\hline
\end{tabular}

previously, instructional interventions for ELLs should be both linguistically and culturally appropriate. School personnel continue to collect and monitor the student's achievement and assess the learning environment and suitability of instruction. A Tier 2 student who fails to reach identified instructional targets is a candidate to move to Tier 3 once it has been established that he or she truly has received an adequate opportunity to learn. Conversely, a student who makes the expected gains may cycle back to Tier 1 with close observation of the student's continuing progress. Below is a table outlining Tier 2 for ELLs.

\section{Tier 3: Intensive Individual Instruction}

In Tier 3, interventions are more intensive and may be delivered individually or in small groups. The student's progress continues to be closely monitored. RTI models vary in their conceptualization of Tier 3 . In some models, Tier 3 would be considered special education and students who progressed to this tier would automatically qualify for special education services. In other models, children would be provided intensive and individual interventions at this tier while concurrently undergoing an assessment for special education eligibility. In models with four tiers, students would receive intensive and focused interventions in Tier 3, and if they fail to make adequate progress, be moved into Tier 4 . Tier 4 might then be considered special education. Below is a table summarizing Tier 3 for ELLs.

\section{Conclusion}

\section{No More "Business As Usual"}

After the above discussion, it should be apparent that we cannot continue "business as usual” when ELLs are struggling in our classrooms. There is great promise, though, in using an RTI approach, for many reasons. First, the universal screening and progress monitoring called for in the RTI process allow for comparison of students to other similar or "true" peers in their local cohort rather than to national norms. Second, an effective RTI model requires collaboration among all educators (e.g., speech and language therapists, school psychologists, counselors, English as a second language/Bilingual specialist), thereby providing increased opportunities for professional dialogue, peer coaching, and the creation of instruc- 


\section{Tier 3:}

\section{POPULATION: STUDENTS WHO NEED DIFFERENT AND MORE INTENSIVE INSTRUCTION}

SETTING: ALTERNATIVE SETTING

\begin{tabular}{|c|c|}
\hline $\begin{array}{l}\text { STUDENT } \\
\text { CHARACTERISTICS }\end{array}$ & $\begin{array}{l}\text { Achievement continues both at a lower level than like-peers, occurs at a substantially slower rate, } \\
\text { and the student needs individualized instruction in order to learn }\end{array}$ \\
\hline $\begin{array}{l}\text { GUIDING } \\
\text { QUESTIONS }\end{array}$ & $\begin{array}{l}\text { - How many rounds of Tier } 2 \text { instruction has the student had? } \\
\text { - Is there evidence of progress from previous interventions? } \\
\text { - Is the student successful with different curriculum, teaching approaches and an individualized } \\
\text { setting? } \\
\text { - Does the student differ from like "true peers" in the following ways: } \\
\text { - Level of performance? } \\
\text { - Learning slope? } \\
\text { - What are the child's functional, developmental, academic, linguistic, and cultural needs? } \\
\text { - If additional assessments are used, are the instruments technically sound, valid, and used } \\
\text { appropriately for the ELL student? } \\
\text { - Are test results interpreted in a manner that considers student's language proficiency in L1 } \\
\text { and L2 and their level of acculturation? } \\
\text { - Do assessments include information in the student's home language and English? } \\
\text { - Has the student received continuous instruction (i.e., absences do not make up a good portion } \\
\text { of the student's profile)? }\end{array}$ \\
\hline $\begin{array}{l}\text { INSTRUCTION/ } \\
\text { INTERVENTION }\end{array}$ & $\begin{array}{l}\text { - Option of receiving different curriculum from Tiers } 1 \text { and } 2 \\
\text { - Curriculum and instruction address the specific learning needs and progress is carefully monitored } \\
\text { - Standardized cognitive and academic assessment should be conducted at this tier to identify } \\
\text { processing profile } \\
\text { - If cognitive assessment is conducted, native language assessment should be included } \\
\text { - Any standardized test data must be interpreted within the context of student's language } \\
\text { proficiency and acculturation }\end{array}$ \\
\hline $\begin{array}{l}\text { SERVICE } \\
\text { PROVIDER }\end{array}$ & $\begin{array}{l}\text { - Special education teacher or related service provider } \\
\text { - General education teacher responsible for integrating all tiers of instruction into the classroom } \\
\text { - All service providers must collaborate with the ELL specialist }\end{array}$ \\
\hline $\begin{array}{l}\text { NECESSARY } \\
\text { SERVICE PROVIDER } \\
\text { SKILLS }\end{array}$ & $\begin{array}{l}\text { Able to: } \\
\text { - ensure that appropriate instruction was provided in Tiers } 1 \text { and } 2 \\
\text { - accurately monitor student's progress } \\
\text { - develop culturally and linguistically appropriate IEP and plan appropriate individualized } \\
\text { instruction } \\
\text { - instruct appropriately to the student's development level and needs, level of language proficiency } \\
\text { and acculturation }\end{array}$ \\
\hline
\end{tabular}

NOTE: Parental rights and consent may be required at this tier because the student is removed from the general education environment for instruction. Student could be qualified to receive special education services under the eligibility category of Specific Learning Disability and have an Individualized Education Program (IEP) developed at this tier without further assessment.

tional models integrating the best practices of the various fields of education and related services. This collaboration is particularly critical, because the research base for all educational fields, including instruction for ELLs, is growing rapidly. Third, students who are struggling can be identified early and supported before falling too far behind to ever catch up.
Our future rests on the promise of the next generation. Accordingly, we must develop the capacity to respond to an increasingly diverse student population, and ensure that these and all children develop to their fullest potential. By building on the cultural wisdom and linguistic knowledge students bring with them, we can help all children succeed.

\section{References}

Adelman, H.S. (2001). LD: The next 25 years. Journal of Learning Disabilities, 25(1), 17-22.

Artiles, A. J., \& Klingner, J. K. (Eds.). (2006). Forging a knowledge base on English language learners with special needs: Theoretical, population, and technical issues. Teachers College Record, 108, 2187-2438. [Special issue] 
Batsche, G., Elliott, J., Graden, J., Grimes, J., Kovaleski, J., Prasse, D. et. al.(2005). Response to intervention: Policy considerations and implementation. Alexandria, VA: National Association of State Directors of Special Education.

Delpit, L. (1995). Other people's children: Cultural conflict in the classroom. New York: The New Press.

Donovan, S. \& Cross, C. (2002). Minority students in special and gifted education. Washington, DC: National Academies Press.

Freire, P., \& Macedo, D. (1987). Literacy: Reading the word and the world. New York: Bergin \& Garvey.

Fuchs, D., Mock, D., Morgan, P.L., \& Young, C.L. (2003). Responsiveness-to-intervention: Definitions, evidence, and implications for the learning disabilities construct. Learning Disabilities Research \& Practice, 18(3), 157-171.

Gay, G. (1989). Ethnic minorities and educational equality. In J.A. Banks \& C.A. Banks (Eds.), Multicultural education: Issues and perspectives (pp. 167-188). Boston, MA: Allyn and Bacon.

Hosp, J.L. \& Rechsley, D.J. (2003). Referral rates for intervention or assessment: A meta-analysis of racial differences. The Journal of Special Education, 37(2), 67-80.
Klingner, J. K., Artiles, A. J., Barletta, L. M. (2006). English Language Learners who struggle with reading: Language acquisition or learning disabilities? Journal of Learning Disabilities, 39, 108-128.

Macedo, D., \& Bartolome, L.I. (1999). Dancing with bigotry: Beyond the politics of tolerance. New York: Palgrave.

Mellard, D. (2004). Understanding responsiveness to intervention in learning disabilities determination. Retrieved July 1, 2005, from www.nrcld.org/html/information

Ortiz, A.A. (1997). Learning disabilities concomitantly with linguistic differences. Journal of Learning Disabilities, 30, 321-333.

Stacks, A.M. (2005). Using an ecological framework for understanding and treating Externalizing behavior in early childhood. Early Childhood Education Journal, 32(4), 269-278.

Waxman, H., Tellez, K., \& Walberg, H.J. (2004). Improving teacher quality for English language learners: Reports and next-step recommendations from a national invitational conference. The LSS Review. The Mid-Atlantic Regional Educational Laboratory. Temple University, Philadelphia, PA.

\section{Building Culturally Responsive Classrooms}

A Guide for K-6 Teachers

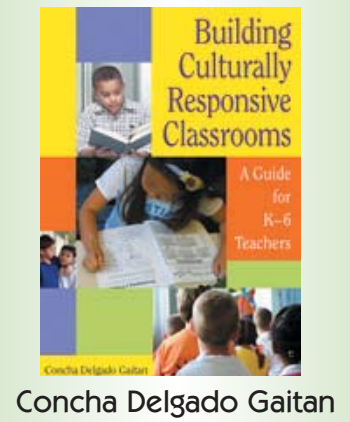

This invaluable resource covers the topics of classroom discipline, classroom arrangement, and parent and community involvement in order to create a culturally inclusive learning setting. Each accessible, user-friendly chapter contains:

- A personal reflection from a teacher

- The latest research and best practices

- A rich case example

- Guiding questions, reflective questions, and classroom applications

\$5809 . . \$30.95

To order call 1-888-232-7733 $\dot{\delta}$. Council tor or visit www.cec.sped.ors

\section{Our Knowledge. At your Fingertips.}

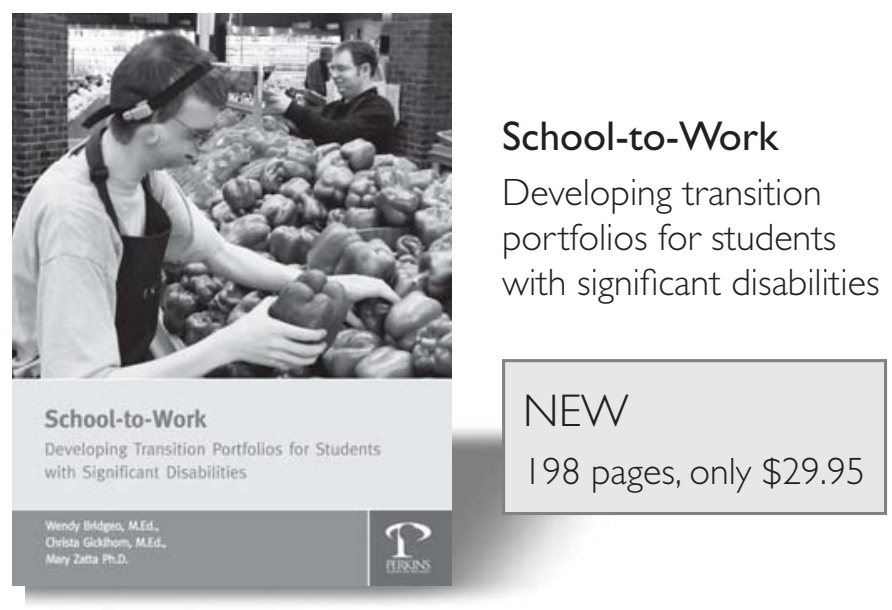

\section{Other Recent Publications: \\ Beyond Pegboards \\ A guide for teaching adolescent students with multiple disabilities}

\section{Welcoming Students with Visual Impairment to Your School \\ A guide for training public school personnel and families about the needs of students with vision loss}

